\title{
3D VISUALIZATION OF A TIMBER FRAME HISTORIC BUILDING: PARTITE USAGE AND ITS IMPACT ON THE STRUCTURAL SYSTEM
}

\author{
S. Günay ${ }^{\text {a }}$ \\ ${ }^{a}$ Canadian University Dubai, School of Architecture \& Design \\ Dubai, UAE - srkngny@gmail.com
}

KEY WORDS: 3D Visualization, Timber Frame Structure, Multi-Layered Building

\begin{abstract}
:
Throughout their lifetime, historic buildings might be altered for different kind of usage for different purposes. If this new function or new usage requires utilization of the building in separate units, this separation might affect the historic building's functionality and structure and as a result its overall condition.

Yorguc Pasa Mansion conservation project was prepared as a part of the Middle East Technical University (METU) Master's Program in Documentation and Conservation of Historic Monuments and Sites for the historic Yorguc Pasa Mansion. The mansion is a 19th century Ottoman Period timber frame building in Amasya, a Black Sea Region city in Turkey that has traces from different civilizations such as Hittites, Greeks, Romans and Ottomans.

This paper aims to discuss the affects of the partite usage on structural conditions of timber frame buildings with the case study of Amasya Yorguc Pasa Mansion through the 3D visualized structural systems.
\end{abstract}

\section{INTRODUCTION}

\subsection{Amasya, a Multi-Layered City}

Historic settlements with edifices from different periods are known as "Multi-Layered Cities". Amasya, a historic city in Northern Anatolia, is a very good example for a settlement which was formed over the years with exceptional buildings that have traces from different civilizations and different periods of times over the time span of its existence.

Urban and architectural development in the city dates back to over 7000 years. As an important settlement for each civilization, it also served as educational and religious center as well as the capital for Pontus Kingdom. Other civilizations that left mark in the city are Hittites, Persians, Hellens, Romans, Byzantines and Ottomans.

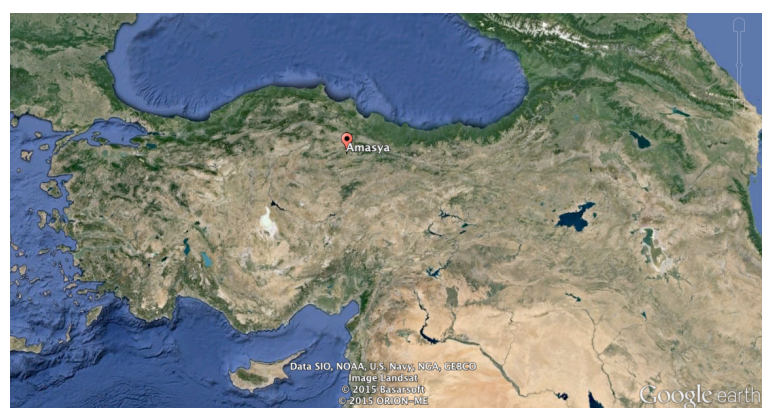

Figure 1. Location of Amasya - Turkey

\subsection{Yorguc Pasa Mansion Project}

The river Yesilirmak, ancient Iris, divides the city of Amasya into two areas within a valley that is shaped by the mountains Harsena and Ferhat. Yorguc Pasa Mansion takes place in the historic Hatuniye District of Amasya that is located alongside Yesilirmak River.

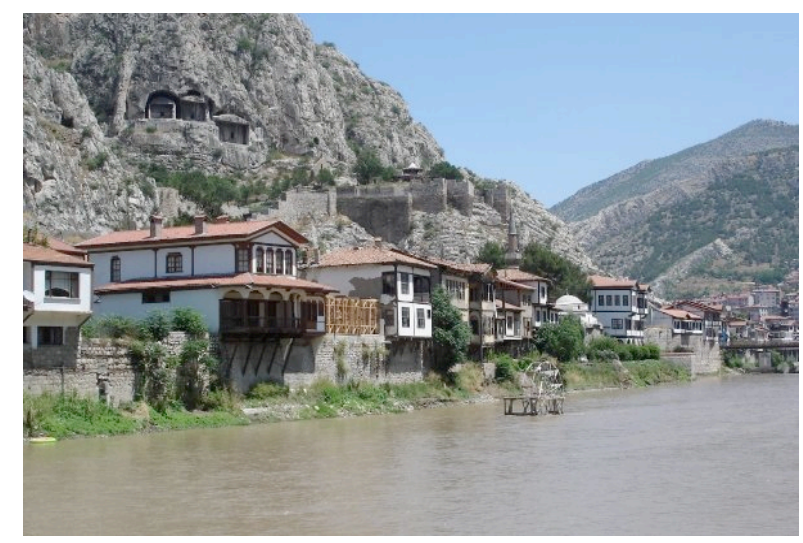

Figure 2. Hatuniye District

Hatuniye District consists of many historic mansions, mosques, hamams, medreses and defensive buildings. Similar to other buildings alongside the river, Yorguc Pasa Mansion is built on top of Roman period city walls and it has the longest facade amongst the other riverside mansions, which differentiates itself from the other historic buildings in the district. 


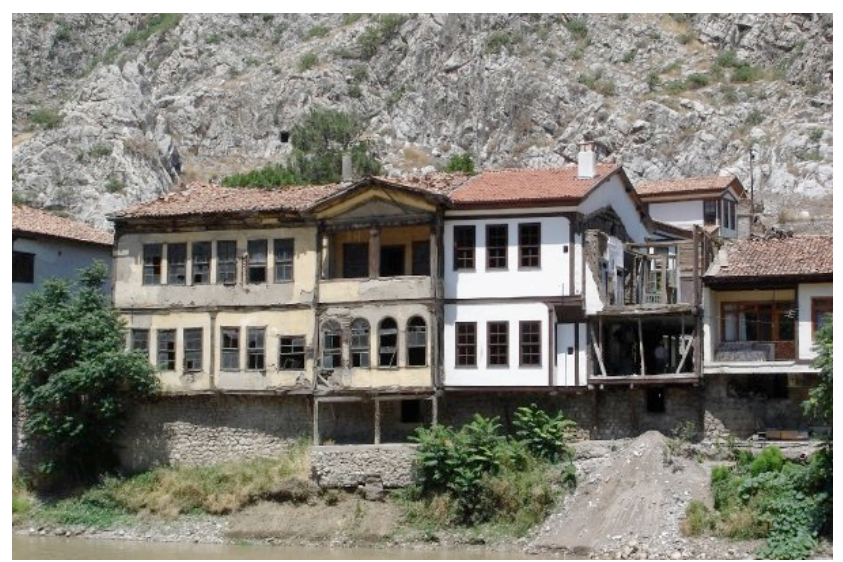

Figure 3. Yorguc Pasa Mansion before restoration

\subsection{The Method}

Conservation project for Yorguc Pasa Mansion developed in four main stages;

- Literature research and collection of historic documents

- Site survey and data collection at the building site

- Evaluation and Analysis

- Developing Conservation Decisions

During pre-site survey, various sources have been studied for the research about the city, Hatuniye district and the building itself. This stage was important because of the definition of the data topics in order to have an efficient data collection period during the site survey. In addition to that, different prior scholarly works have been studied and historic and general information about the building has been gathered.

During the site survey of the building data related to the physical and structural condition of the building were collected. Total Station has been used in order to document the existing condition of the building together with its nearby surroundings. In addition to the documentation information, some material samples also have been collected for the laboratory studies. This includes; paint samples, mortar samples, infill material samples, wood samples etc.

Following the data collection throughout the site survey documentation drawings have been prepared for the building in different formats. Site plan that includes the nearby surrounding buildings, plans, sections elevations, furniture details, door and window details, reflected ceiling plans were some of the drawings that have been prepared for the building. During this stage the existing condition of the building have been identified from functional and usage point of view as well as the structural and material condition of the building elements. This was achieved by analysing the collected material samples in laboratory environment.

Consequently, by evaluating the building's existing situation and considering the possible future function of the mansion, conservation principles have been decided. These proposals were introduced after the evaluation of the problems and potentials of the building and its immediate surroundings.

\section{3D VISUALIZATION OF THE TIMBER FRAME STRUCTURE}

Similar to the city of Amasya, in this building it is possible to see a multilayered formation that has traces from different historic periods. With its identified four intervention periods, the mansion is in a divided condition that has lost its original plan and facade organization. These interventions lead the usage of the house in three different sections, and each section of the mansion is affected by this division differently due to the different usage type. According to the new space needs, the rooms were divided by walls or new rooms were created without considering the original spatial principles. In addition to the changes in spatial organization of the building, this divided usage caused many structural and material decay in the building. Because of the mentioned different usage, the type of decay on structural and material elements of the building is varied.

Documentation of Yorguc Pasa Mansion has been done by using Total Station and collecting various coordinates, in order to prepare plans, sections and elevations of the building. Additionally, photogrammetric rectification software has been used in order to prepare the different interior and exterior elevations of the building. Details for the doors, windows, wall units, fireplaces etc. has been measured by using conventional techniques.

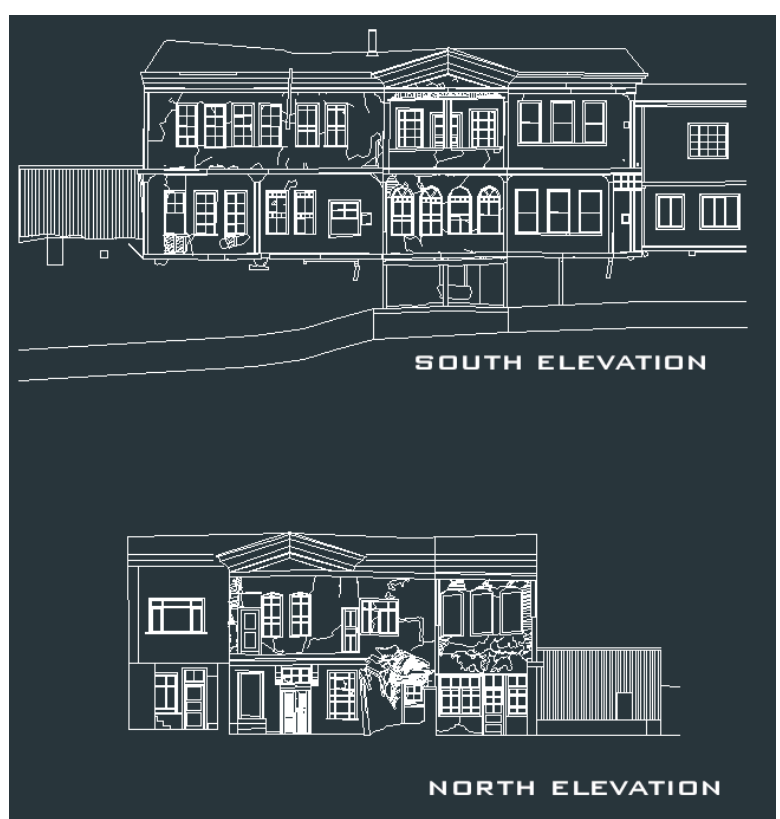

Figure 4. CAD Drawings

\subsection{CAD Drawings}

With Yorguc Pasa Mansion project following drawings were used as reference for the construction of the 3D model;

- Plan drawings of each floor

- Elevation and Section drawings

- $\quad$ RCP drawings

- Ceiling details 
From the survey drawings several other drawings have been prepared in order to define the potentials and problems of the building. One of these drawings was reflected ceiling plan drawings with the identification of the structural elements. In addition to digital documentation, each ceiling was studied in terms of the location of the structural elements.

Visible structural elements were identified with the documentation and invisible structural elements were located with the help of the traces that were followed within the building.

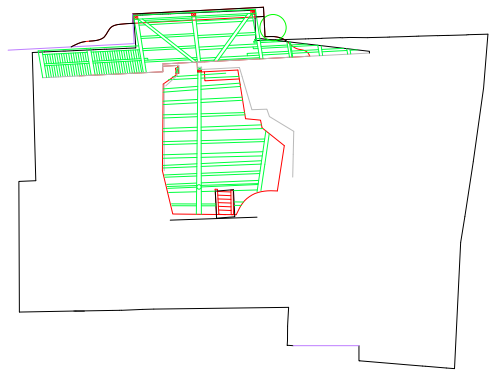

Figure 5. Basement Structural RCP

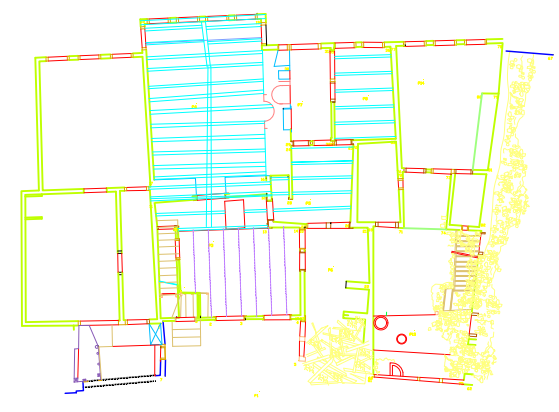

Figure 6. Ground Floor Structural RCP

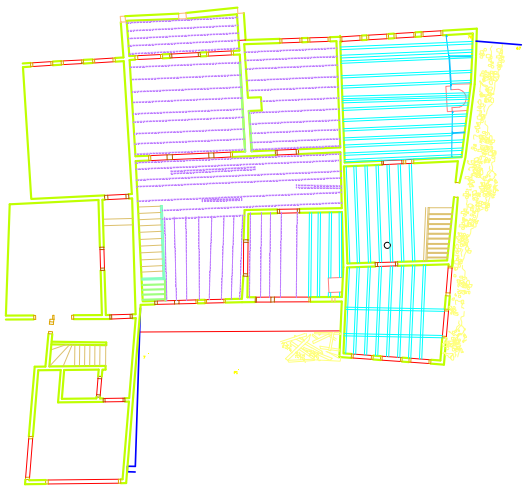

Figure 7. First Floor Structural RCP

\subsection{D Modeling}

3D structural model was created by using visual documents and sketches as reference structural elements which were visible from the facades, especially in the western façade, and also from the interior of the building. For instance, girders seen from the uncovered ceilings of the interior spaces are used in the drawing.

Finding the girder axis from the nails' location on the timber floor covering was another technique to identify the structure. Due to the planks, main structural elements (both vertical and horizontal) on the exterior walls of the building were found as they were visible.

Besides the exterior ones, invisible structural elements on the interior spaces were placed by using the traces and by completing the frames. The comparison between the ground floor and the first floor helped to complete the frame construction principal of the secondary structural elements. These elements were visible from a small uncovered surface on the south façade. This information obtained from a small unit, was applied to whole model. As a result of this a legend was prepared to show the difference between the visible and invisible structural elements.

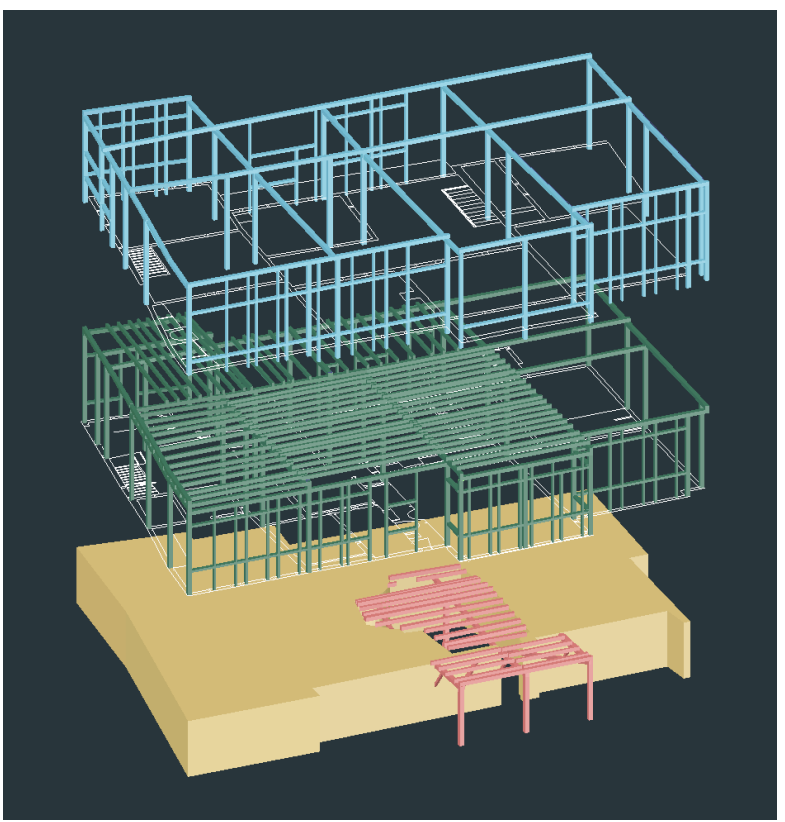

Figure 8. Timber Frame Structure

In order to understand the impact of partite usage on structural system of the building, timber frame structural elements have been visualized in $3 \mathrm{D}$ environment. With the 3D model, different periods and different structural problems have been identified and analyzed. 3D model has been created in CAD environment after the site survey with the identification of the visible and hidden structural elements. With the help of point clouds that has been documented at the site by Total Station, these different type of structural elements have been generated and color coded according to the identification types. Various structural problems were identified within the timber frame structure, due to the partite usage of the historic building. These structural problems than cross checked with the identified periods of the building and areas with different levels of structural problems visualized in CAD environment. 


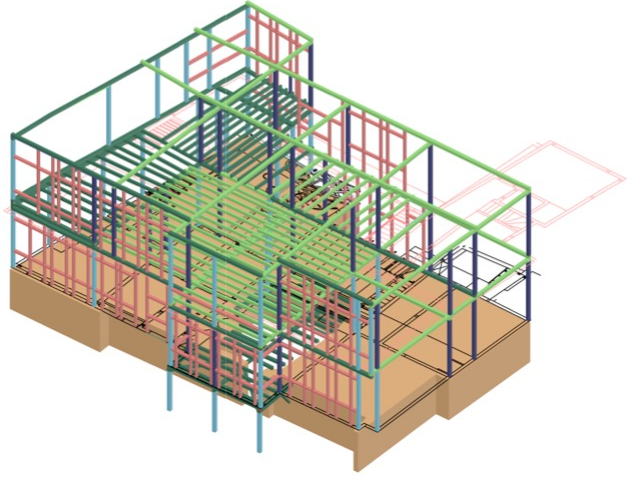

Figure 4. 3D Structural Model with Identified Visibility Status

Yorguc Pasa Mansion consists of three different structural and material conditions that have been developed through four different intervention periods that has been identified through restitution proposals. Over the years the building has been used by multiple owners by dividing the building vertically and horizontally in order to occupy maximum amount of inhabitants. At the time of the documentation, three different main partite usages have been identified according to the structural and material condition analysis of the building.

Three different partite usage of the building is described as eastern section, central section and western section. At the time of the study only the eastern section of the building was inhabited and it was in good structural condition. Although eastern section of the building was in relatively better condition, central section of the building was also in good condition except for some minor material decay. However the most critical condition of the building was the western section of the mansion, where due to the roof collapse, the structure and materials of the building were exposed to the weather conditions and severe decay was observed throughout this section of the building.

\section{CONCLUSION}

Yorguc Pasa Mansion is a good example to observe the different impacts of partite usage on a historic timber frame structure. It is essential to visualize this impact with the identification of the structural elements in $3 \mathrm{D}$ CAD environment. With the help of the 3D model it was possible to follow the changes in the structural system due to the partite usage of the building. This also provided input for the conservation decision making process of the historic structure.

It was also possible to identify the amount of structural elements with severe deterioration problems which gave a reference for the different intervention types that was proposed for the building. Further studies could be followed in order to manage the data and propose structural solutions for the problematic areas of the mansion.

The values and potentials of the building differentiate due to the partite usage from one section to another as well as the structural problems. Continued inhabited section enabled to have edifices of lost architectural elements and ornamentation details in the other two sections. This gave a chance to distinguish more structured interventions where the lost information in one section could be found in the other section where partite usage could be identified as a positive outcome for the building.

\section{ACKNOWLEDGEMENT:}

"Yorguc Pasa Mansion Conservation Project" has been prepared through the Rest.507 Course in Graduate program in Restoration, METU Ankara, by the students; G. Can, O. Cöcen, H. Eldek, E. Erdem, S. Günay, I. Keskin, K. Şahlan under the supervision of Assoc. Prof. Dr. N. Şahin Güçhan, Assoc. Prof. Dr. G. Asatekin and Asst. Prof. Dr. G. Bilgin Altınöz.

\section{REFERENCES:}

Altinoz, G. B. (2002). "Assessment Of Historical Stratification In Multi-Layered Towns As A Support for Conservation Decision-Making Process: a Geographical Information Systems (GIS) Based Approach Case Study: Bergama”, Unpublished PhD Thesis, Ankara, METU

Etyemez L. (2011) Assessing the Integration of Historical Stratification with the Current Context in Multi-Layered Towns. Case Study: Amasya, Unpublished Masters Thesis, Ankara, METU

Urak, G., Evaluation and Analysis of Urban Formation and Historic Buildings of the city of Amasya, Gazi University 1994

Karakul, O., New Buildings in Old Settings: Riverfront Buildings in Amasya, METU 2002

Quintero M. S., (2003) The use of 3D Techniques of Documentation and Dissemination in Studying Built Heritage, Leuven 